\title{
Vaccination of pigs against pseudorabies virus with plasmid DNA encoding glycoprotein D
}

\author{
Bart L. Haagmans ${ }^{\mathrm{a}, *}$, Eugene M.A. van Rooij ${ }^{\mathrm{b}}$, Mark Dubelaar ${ }^{\mathrm{a}}$, \\ Tjeerd G. Kimman $^{\text {c }}$, Marian C. Horzinek ${ }^{\mathrm{a}}$, Virgil E.C.J. Schijns ${ }^{\mathrm{a}, 1}$, \\ Andre T.J. Bianchi ${ }^{b}$ \\ ${ }^{a}$ Virology Unit, Department of Infectious Diseases and Immunology, Veterinary Faculty, Utrecht University, Yalelaan 1, 3584 CL Utrecht, \\ Netherlands \\ ${ }^{\mathrm{b}}$ The Department of Mammalian Virology, Institute for Animal Science and Health, ID-DLO, Lelystad, Netherlands \\ ${ }^{\mathrm{c}}$ The Research Laboratory for Infectious, Diseases, National Institute of Public Health and the Environment, Bilthoven, Netherlands
}

Received 8 July 1998; accepted 18 September 1998

\begin{abstract}
We analysed the ability of a plasmid carrying the gene encoding glycoprotein D (gD) of pseudorabies virus (PRV) to induce humoral and cell-mediated immune responses and assessed the protection provided by PRV-gD DNA vaccination against challenge infection with PRV. Immunization with plasmid PRV-gD induced neutralizing antibodies and lymphocyte proliferative responses both in mice and pigs. Moreover, when challenged with virulent PRV six weeks following the last immunization, PRV-gD DNA vaccinated pigs excreted virus for a significantly shorter period and showed less clinical symptoms than pigs vaccinated with a control plasmid. Thus, in the target animal, DNA vaccination with PRV-gD DNA induces protective immunity against challenge infection. (C) 1999 Elsevier Science Ltd. All rights reserved.
\end{abstract}

Keywords: Pseudorabies virus; DNA vaccination; Glycoprotein D

\section{Introduction}

Pseudorabies or Aujeszky's disease is caused by an alphaherpesvirus and leads to mortality in piglets and to latent infections in adult pigs (for a review see Ref. [1]). With the notable exception of man, vertebrates are highly susceptible to pseudorabies virus (PRV) and succumb mostly to infections of the nervous system. The disease is characterized by neurological signs, severe respiratory illness, abortions, reduced litter size and decreased growth rates of survivors. Third-generation recombinant PRV vaccines presently employed in the field are virus strains missing genes or harboring defective genes. Irrespective of their sophistication they have a major disadvantage: they contain replication competent virus. Therefore the virus may

\footnotetext{
* Corresponding author. Fax: + 31-30-253-6723; e-mail: b.haagmans@vetmic.dgk.ruu.nl.

${ }^{1}$ Current address: Intervet International B.V., Boxmeer, The Netherlands.
}

persist and exert immunosuppressive effects in animals, spread to other animals and even revert to virulence.

The observation that delivery of plasmid DNA by intramuscular injection or other routes (e.g. intradermal or mucosal) led to protein expression [2,3] has opened new avenues to vaccination. When tested in several animal model systems, DNA immunization induced a vigorous long-lived immune response [4]. Ulmer et al. [5] first demonstrated the efficacy of DNA immunization against a viral infection; injection of DNA encoding the influenza A virus nucleoprotein protected mice from lethal challenge infection. Subsequent studies in mice have shown that DNA immunization can induce neutralizing antibodies (Abs) and cytotoxic T-cells against several viral pathogens, including rabies virus [6], herpes simplex virus [7, 8], lymphocytic choriomeningitis virus $[9,10]$, murine cytomegalovirus [11] and papilloma virus [12]. However, only few studies have addressed the question whether DNA vaccines induce effective and long lasting immunity in the natural host [13-15]. 
Previously, we and others have shown that protection against PRV can be achieved in mice and pigs [1621]. The glycoprotein $\mathrm{D}(\mathrm{gD})$, which permits efficient infection of target cells $[22,23]$ is one of the most potent immunogens of the virus [24]. Moreover, vaccination of mice or pigs with recombinant $\mathrm{gD}$ or with recombinant vectors harboring the $\mathrm{gD}$ gene conferred protection to the animals [16-18]. Although neutralizing (monoclonal) Abs directed against $\mathrm{gD}$ are able to protect animals against PRV [25], the levels of Abs present in vaccinated animals do not always correlate with protection, indicating that $\mathrm{T}$-cell mediated mechanisms also contribute to immunity. Apart from the need for new PRV vaccines, available knowledge about PRV makes it particularly suitable for studying the potential of DNA vaccination in pigs. Here we describe initial immunization studies using plasmid DNA expressing the PRV-gD gene.

\section{Material and methods}

\subsection{Animals}

Female C57BL/6 and BALB/c mice were purchased from the breeding facility of the Central Animal Laboratory Utrecht. The mice were housed in filter top cages and immunized at 4-5 weeks of age. 10- to 12-week-old Dutch landrace pigs from the specifiedpathogen-free herd of the ID-DLO were used. The pigs were born from unvaccinated sows, free from Abs against PRV before the start of the experiment and they were randomly assigned to the experimental groups. The animal experiments had been approved by the Institutional Animal Welfare Committee.

\subsection{Virus}

The seventh cell culture passage of strain NIA-3 [26], prepared in secondary porcine kidney cells as described by Kimman et al. [19], was used for challenge inoculation.

\subsection{Cloning and DNA preparation}

A HindIII/EcoRI fragment from plasmid pMZ33, containing the full length $\mathrm{gD}$, was cloned into vector VR1012 (Vical, San Diego, USA), which contains the human cytomegalovirus immediate early promoter, intron $\mathrm{A}$, the bovine growth hormone polyadenylation processing signal and the gene encoding kanamycin resistance (Fig. 1a). The VR1012 plasmid lacking the PRV-gD DNA insert served as a control. Plasmids were grown in the HB101 strain of Escherichia coli and purified using Qiagen columns (Westburg, The Netherlands).

\subsection{Immunocytochemistry}

L-Cells were grown on coverslips and transfected with $1 \mu \mathrm{g}$ plasmid DNA using lipofectin (Gibco) or infected with PRV at a multiplicity of infection of 3; a

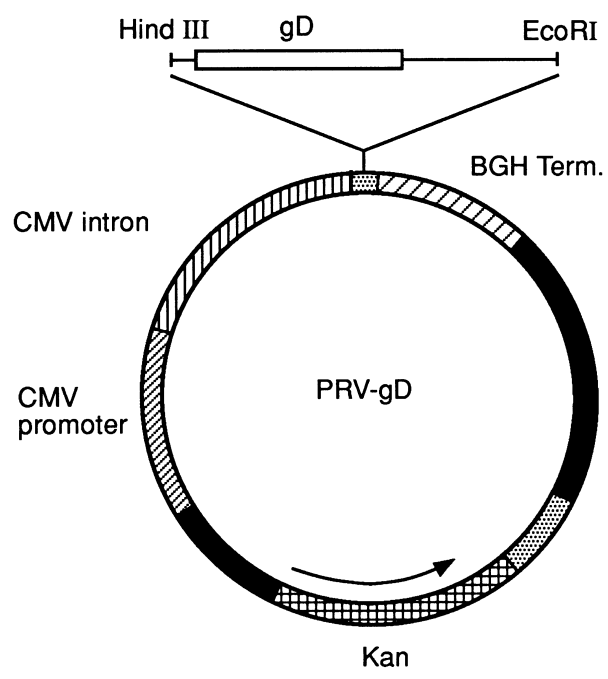

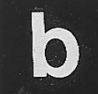

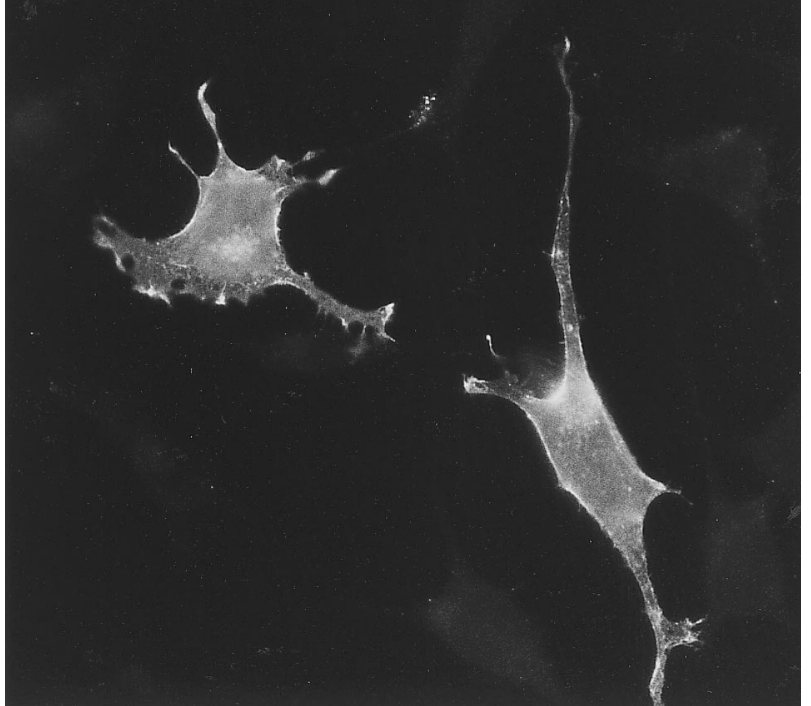

Fig. 1. (a) Schematic representation of PRV-gD, containing cytomegalovirus immediate-early gene enhancer and promoter (CMV promoter) plus intron A (CMV intron) driving expression of PRV-gD. The bovine growth hormone polyadenylation processing signal (BGH term) and the gene encoding kanamycin resistance (Kan) are indicated. (b) Expression of gD in PRV-gD DNA transfected cells. L-Cells were transfected with PRVgD DNA and $24 \mathrm{~h}$ later the cells were fixed and stained with a monoclonal Ab against gD (magnification $400 \times$ ). 
after $24 \mathrm{~h}$ the cells were fixed with $4 \%$ formaldehyde (15 min) and permeabilized with $70 \%$ ethanol $(5 \mathrm{~min})$. After blocking with $20 \%$ normal goat serum (30 min), cells were incubated with a monoclonal $\mathrm{Ab}$ against $\mathrm{gD}$ [27] (1:200 dilution, $1 \mathrm{~h}$ at room temperature). After rinsing (all washes were in PBS), they were incubated with biotinylated goat anti-mouse $\mathrm{IgG} \mathrm{Ab}$ (Dakopatts) followed by three washes. Avidin-coated fluorescein isothiocyanate complexes (Nordic) were used at a 1:100 dilution for $30 \mathrm{~min}$. Coverslips treated with an irrelevant monoclonal $\mathrm{Ab}$ served as negative controls. The preparations were mounted in PBS-glycerol containing 2\% 1,4-diazabicyclo(2,2,2)octane and examined in an epifluorescence microscope.

\subsection{Experimental protocol}

Mice $(n=5)$ were anesthetized by intraperitoneal (i.p.) injection of $50 \mu \mathrm{l} \mathrm{Nembutal}$ and immunized with $50 \mu \mathrm{g}$ plasmid $/ 50 \mu \mathrm{l}$ saline in the musculus tibialis and intradermally at the base of the tail. Twelve days later the spleens were removed and single cell suspensions of splenocytes were tested for PRV specific proliferative activity. Muscle tissue was fixed in $4 \%$ formaldehyde and embedded in paraffin; sections $(3 \mu \mathrm{m})$ were deparaffinated and counterstained using hematoxylin and eosin. Mice were bled from the retro-orbital plexus and their sera were analyzed for the levels of virus neutralizing (VN) Abs. All mice were challengeinoculated via the i.p. route with 250 plaque forming units (p.f.u), corresponding to $250 \mathrm{LD}_{100}$ of virulent PRV strain NIA-3.

Pigs were vaccinated three times with an interval of 4 weeks with $400 \mu \mathrm{g}$ plasmid DNA in PBS in the (epi)dermis and in the muscle behind the ear using a 22 gauge needle $(200 \mu \mathrm{g}$ of plasmid was administered at each site). At weekly intervals, samples were taken to assess the induction of $\mathrm{VN}$ Abs and cell-mediated immune responses. Six weeks after the third vaccination, all pigs were challenged intranasally with $10^{5}$ p.f.u. of virulent wildtype strain NIA-3 per animal. Humoral and cell-mediated immune responses were recorded until day 21 after challenge; clinical signs, rectal temperatures and body weights were recorded for 14 days. Virus excretion was monitored by collection of oropharyngeal fluid (OPF) from the day before until day ten after challenge using swabs. Swabs were extracted with $4 \mathrm{ml}$ of Dulbecco's minimal essential medium (DMEM) supplemented with 2\% fetal bovine serum and antibiotics. To determine the virus content per gram OPF, the weight of the collected fluid was measured after centrifugation of the swabs in a homemade container.

\subsection{Proliferative lymphocyte responses}

Twelve days after immunization, erythrocytedepleted single cell suspensions were prepared from the spleens of mice. Splenocytes were cultured in 96-well round bottom plates at a density of $10^{5}$ cells per well in RPMI 1640 medium containing 10\% FCS, 2 mM Lglutamine, $100 \mathrm{U} / \mathrm{ml}$ penicillin and $100 \mu \mathrm{g} / \mathrm{ml}$ streptomycin. Purified inactivated PRV or concanavalin (Con) A was added at concentrations of 1.25 and 5 $\mu \mathrm{g} / \mathrm{ml}$, respectively. After $72 \mathrm{~h}$ incubation at $37^{\circ} \mathrm{C}$ in a $5 \% \mathrm{CO}_{2}$ atmosphere the cultures were pulsed with 1.0 $\mu \mathrm{Ci}\left[{ }^{3} \mathrm{H}\right]$-thymidine (Amersham) for another $16 \mathrm{~h}$. Cells were harvested on glass filters and the incorporated radioactivity was measured in a Betaplate scintillation counter (LKB-Wallac). The data represent the mean values \pm S.E.M. of $\left[{ }^{3} \mathrm{H}\right]$-thymidine uptake of triplicate cultures determined in 3 mice/group.

Peripheral blood mononuclear cells (PBMC) from pigs were analyzed for specific PRV responses according to Kimman et al. [28]. Briefly, PBMC were isolated from heparinized blood samples by density gradient. The isolated PBMC were seeded in 96-well flat-bottom plates (Greiner) at a density of $5 \times 10^{6}$ cells $/ \mathrm{ml}$ in RPMI 1640 medium containing $10 \%$ porcine serum, 2 $\mathrm{mM}$ L-glutamine, $50 \mu \mathrm{M}$ 2-mercaptoethanol, $200 \mathrm{U} / \mathrm{ml}$ penicillin, $200 \mu \mathrm{g} / \mathrm{ml}$ streptomycin and $100 \mathrm{U} / \mathrm{ml}$ mycostatin. To $100 \mu \mathrm{l}$ of leucocyte suspension, $50 \mu \mathrm{l}$ of live virus preparation containing $5 \times 10^{6}$ p.f.u. $/ \mathrm{ml}$ of the PRV strain NIA-3 was added. Control wells were incubated with supernatant from non-infected cells. In each test four wells were incubated with $5 \mu \mathrm{g} / \mathrm{ml}$ of Con $\mathrm{A}$ as a positive control. After 4 days incubation in a humified incubator at $37^{\circ} \mathrm{C}$ in a $5 \% \mathrm{CO}_{2}$ atmosphere, the cultures were pulsed with $0.4 \mu \mathrm{Ci}\left[{ }^{3} \mathrm{H}\right]$-thymidine for another $16 \mathrm{~h}$. Cells were harvested and the incorporated radioactivity was measured in a Betaplate scintillation counter. Proliferation is expressed as the number of counts of PRV-stimulated PBMC minus the number of counts of the medium-stimulated PBMC (delta counts). The data represent the mean values \pm S.E.M. of $\left[{ }^{3} \mathrm{H}\right]$-thymidine uptake of quadruplicate cultures.

\subsection{PRV Abs}

VN Abs were detected by incubating sera with 100 (range: $30-300)$ tissue infective doses $\left(\right.$ TCID $_{50}$ ) of PRV strain NIA-3 for $24 \mathrm{~h}$ at $37^{\circ} \mathrm{C}$ as described [29]. Titres are expressed as $\log _{10}$ of the reciprocal of the highest serum dilution inhibiting cytopathogenic effect in 50\% of the cultures. Prior to testing, sera were heat-treated $\left(30 \mathrm{~min}\right.$ at $\left.56^{\circ} \mathrm{C}\right)$ to inactivate complement. Sera were tested for PRV specific antibodies in an ELISA as described earlier [21]. 


\subsection{Virus titration}

The amount of virus excretion was measured by virus titration on SK-6 monolayers in DMEM supplemented with $5 \%$ fetal bovine serum, L-glutamine $(0.3 \mathrm{mg} / \mathrm{ml})$, penicillin $(90 \mathrm{U} / \mathrm{ml})$, streptomycin $(100 \mathrm{U} /$ $\mathrm{ml})$ and nystatin $(45 \mathrm{U} / \mathrm{ml})$ in a humidified incubator at $37^{\circ} \mathrm{C}$ with $5 \% \quad \mathrm{CO}_{2}$ as described by Kimman et al. [19].

\subsection{Statistical analysis}

Differences in lymphocyte proliferation responses and virus neutralization titers were tested for statistical significance by analysis of variance (ANOVA). Differences in duration of virus shedding, fever and clinical signs were tested for statistical significance by the non-parametric Mann-Whitney $U$ test. The significance level was set at $95 \%$.

\section{Results}

\subsection{In vitro expression of plasmid $P R V-g D$}

The gene encoding the full-length gD protein from PRV was cloned into the expression vector VR1012 which was subsequently designated as PRV-gD. Expression of the encoded protein from the PRV-gD DNA plasmid was confirmed in tissue culture by transient expression assays; after transfection into L-cells, $\mathrm{gD}$ was detected by immunofluorescence staining using a monoclonal $\mathrm{Ab}$ directed against gD (Fig. 1b). The

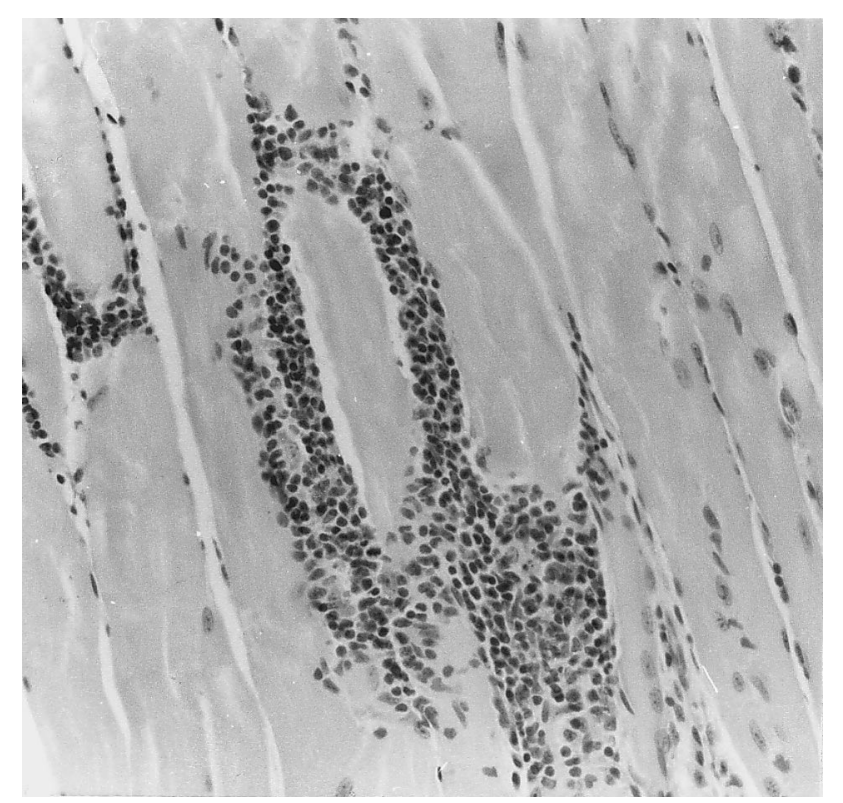

Fig. 2. Lymphocytic infiltration of PRV-gD DNA injected murine muscle tissue (magnification $160 \times$ ).
Table 1

Immunogenicity of PRV-gD DNA in mice

\begin{tabular}{lll}
\hline Immunization $^{\mathrm{a}}$ & Proliferation $(\mathrm{cpm})$ & Serum VN Ab titer \\
\hline Control plasmid & $497 \pm 94$ & $<4$ \\
PRV-gD plasmid & $2663 \pm 721$ & 16 \\
\hline
\end{tabular}

${ }^{\mathrm{a} C} \mathrm{C} 7 \mathrm{BL} / 6$ mice $(n=5)$ were immunized once with $50 \mu \mathrm{g}$ plasmid by the intramuscular and intradermal route.

${ }^{\mathrm{b}}$ Splenocytes were isolated at 12 days post immunization and restimulated with PRV in vitro. Proliferation in the absence of antigen was always $<630 \mathrm{cpm}$.

${ }^{\mathrm{c}}$ Sera were collected at 12 days post immunization. The VN titer is expressed as the reciprocal of the highest dilution of serum which protected greater than $50 \%$ of the cells from cytopathic effects.

protein was present both intracellularly as well as on the cell surface of transfected cells, consistent with the presence of a transmembrane domain in $\mathrm{gD}$. On the basis of immunofluorescence staining, the level of $\mathrm{gD}$ expression was higher in PRV-gD DNA transfected cells than in PRV-infected cells; no staining was observed using irrelevant Abs or cells transfected with the control plasmid (not shown).

\subsection{Immunogenicity of $P R V-g D D N A$ in mice}

In order to assess the ability of the PRV-gD DNA plasmid to induce PRV-specific immune responses, $\mathrm{C} 57 \mathrm{Bl} / 6$ and $\mathrm{BALB} / \mathrm{c}$ mice $(n=5)$ were injected intramuscularly and intradermally with $50 \mu \mathrm{g}$ PRV-gD DNA or control plasmid DNA. As shown in Fig. 2, infiltrating leucocytes were 12 days after immunization with PRV-gD DNA in the injected muscle, but not in

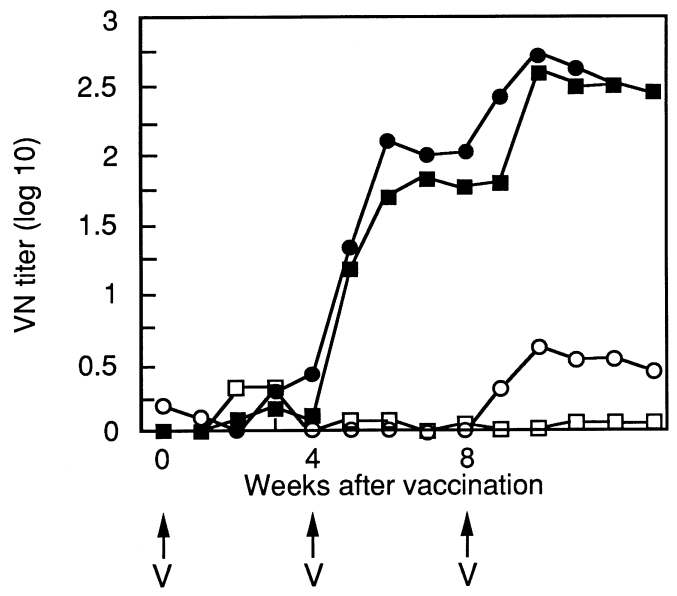

Fig. 3. Induction of serum VN Abs in PRV-gD DNA (filled symbols) and control plasmid (open symbols) immunized pigs. Pigs ( $n=5$, squares) were vaccinated at week 0,4 and 8 (arrows). In addition, the kinetics of $\mathrm{VN}$ Abs from a pilot experiment $(n=3$, circles) are shown. Data are given as geometric mean $\log _{10} \mathrm{VN}$ titre. Pigs vaccinated with PRV-gD had significantly higher $(p<0.05)$ antibody levels than the sham-vaccinated controls after second and third vaccination. 


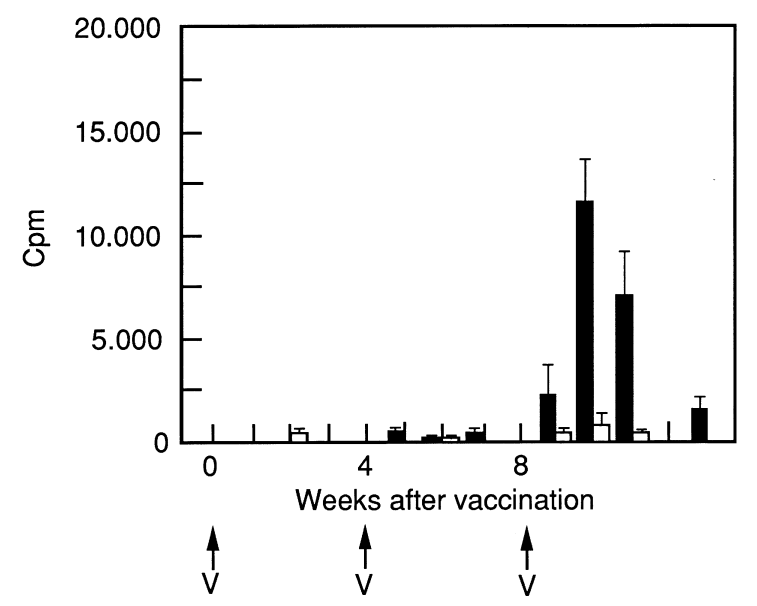

Fig. 4. Induction of cell-mediated immune responses in PRV-gD DNA (filled bars) and control plasmid (open bars) immunized pigs. Data are expressed as arithmetic mean delta counts (number of counts of PRV-stimulated PBMC minus the number of counts of the medium-stimulated PBMC) and S.E.M. Pigs were vaccinated at week 0,4 and 8 (arrows). Pigs vaccinated with PRV-gD had significantly higher $(p<0.05)$ LPT responses than the sham vaccinated controls after the third vaccination.

muscle tissue from mice injected with the control plasmid (not shown). At the same time VN Abs were detected in the sera of mice injected with the plasmid PRV-gD (Table 1). The presence of PRV-specific Abs in $\mathrm{C} 57 \mathrm{Bl} / 6$ and $\mathrm{BALB} / \mathrm{c}$ mice, which further increased upon boost immunization at 4 weeks, was confirmed by ELISA; similar end point titers were found as compared to the VN Abs (not shown). Moreover, mice immunized with PRV-gD DNA generated antigenspecific proliferative responses when restimulated in vitro with inactivated virus (Table 1). However, mice were not protected against a virulent challenge with $250 \mathrm{LD}_{100}$ PRV at 2 weeks after the boost immunization.

\subsection{Immunogenicity of $P R V-g D D N A$ in pigs}

Groups of 5 pigs were immunized with $400 \mu \mathrm{g}$ PRVgD plasmid DNA or control plasmid: $200 \mu \mathrm{g}$ in the (epi)dermis and $200 \mu \mathrm{g}$ in the muscle. Significant VN $\mathrm{Ab}$ titres were detected after the second immunization

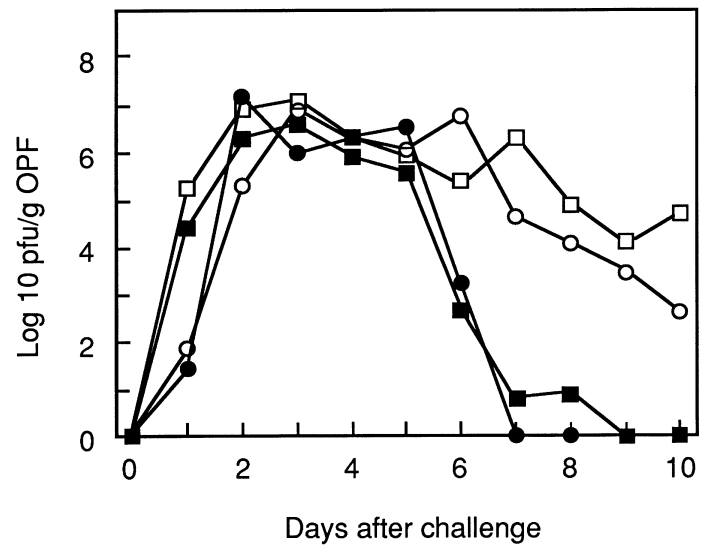

Fig. 5. Virus excretion after challenge infection with PRV strain NIA-3 in PRV-gD DNA (filled symbols) and control plasmid (open symbols) immunized pigs. The kinetics of virus excretion from two different experiments [squares $(n=5)$, circles $(n=3)$ ] are shown. Data are expressed as arithmetic mean $\log _{10}$ virus titre per gram oropharyngeal fluid (OPF).

(Fig. 3) and were boosted after the third immunization, reaching levels comparable to those seen after vaccination with conventional vaccines. These results were similar to those obtained in a preceding pilot experiment (Fig. 3). After the third vaccination, a shortlived PRV-specific lymphocyte proliferative response was detected in the peripheral blood of 4/5 PRV-gD vaccinated pigs (Fig. 4). Thus, immunization of pigs with PRV-gD resulted in the induction of high levels of $\mathrm{VN}$ Abs and relatively weak cell-mediated immune responses.

\subsection{PRV challenge of PRV-gD DNA immunized pigs}

Six weeks after the third vaccination, pigs were challenge-inoculated intranasally with $10^{5}$ p.f.u. of PRV strain NIA-3 to assess the protection provided by DNA vaccination. Vaccinated pigs excreted virus for a significantly shorter period $(p<0.05)$ as compared with the control vaccinated pigs (Table 2). Virus excretion started from day 1 and peaked on day 2 to 5 with titres between $10^{6}-10^{7}$ p.f.u./g OPF in vaccinated and non-vaccinated pigs. However, in PRV-gD vaccinated pigs virus excretion started to cease from day 6

Table 2

Duration of virus excretion, fever and clinical signs after intranasal challenge infection of pigs with PRV strain NIA-3

\begin{tabular}{lllll}
\hline Immunization & Mortality & Virus excretion $^{\mathrm{a}}$ & Fever $^{\mathrm{b}}$ & Clinical signs $^{\mathrm{a}}$ \\
\hline PRV-gD plasmid & $0 / 5$ & $6.4 \pm 0.9$ & $3.6 \pm 0.9$ & $4.8 \pm 0.3$ \\
Control plasmid & $1 / 5$ & $10 \pm 0.0$ & $5.5 \pm 0.6$ & $10.8 \pm 0.6$ \\
\hline
\end{tabular}

\footnotetext{
${ }^{\mathrm{a}}$ Days (mean \pm standard deviation).

${ }^{b}$ Number of days during which the mean body temperature of the animals was above $40^{\circ} \mathrm{C}$. Differences between the PRV-gD and control group in duration for virus excretion, days of fever and clinical signs are statistically significant $(p<0.05)$.
} 


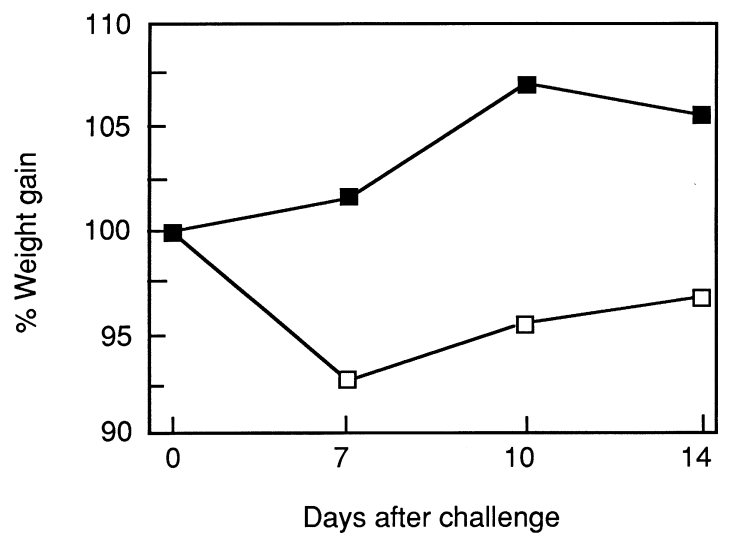

Fig. 6. Mean percent body weight gain after challenge infection with PRV strain NIA-3. The weight at the day of challenge infection is used to calculate the relative increase in body weight at days 7, 10 and 14. Shown are PRV-gD DNA (solid squares) and control plasmid (open squares) immunized groups.

whereas control animals excreted virus until day 10 (Fig. 5). Similar results were observed in a preceding pilot experiment (Fig. 5).

After challenge, PRV-gD DNA vaccinated pigs seroconverted quicker and stronger than non-vaccinated animals; in PRV-gD DNA vaccinated pigs Ab titres started to increase from day 6 onwards and reached mean $\mathrm{VN}$ titres of $10^{4.8}$ at day 21 post challenge. In control-vaccinated pigs, $\mathrm{Ab}$ titres increased at day 10 onwards reaching mean titres of $10^{3.5}$ at day 21 post challenge. There was no significant difference in the kinetics and height of the lymphocyte proliferation responses between both groups of pigs; all started to develop lymphocyte proliferation responses at day 6 (not shown).

Control animals suffered severe growth retardation as they had lost on average $7.2 \%$ of their body weight at day 7 after challenge. In contrast, pigs vaccinated with PRV-gD DNA showed a slight increase of body weight. At day 10 after challenge all PRV-gD DNA vaccinated pigs had regained their initial body weight whereas none of the control pigs had regained their initial body weight 14 days after challenge (Fig. 6). Moreover, PRV-gD vaccinated pigs had a significantly shorter period of fever and clinical signs as compared to control-vaccinated pigs (Table 2). One animal in the control plasmid vaccinated group succumbed to the infection, whereas all PRV-gD DNA vaccinated animals survived. We conclude that DNA immunization of pigs with PRV-gD provides partial protection against a high dose of challenge.

\section{Discussion}

In this report we show that DNA vaccination with a plasmid encoding glycoprotein D of PRV in pigs, an economically important target animal, stimulates effectively humoral immune responses and provides protective immunity against a virulent challenge with the NIA-3 virus strain. We have checked expression of the PRV-gD plasmid in vitro as well as in mice of different genetic background: in both $\mathrm{BALB} / \mathrm{c}$ and $\mathrm{C} 57 \mathrm{BL} / 6$ strains the PRV-gD plasmid induced humoral and cellular immune responses. PRV-gD DNA vaccinated pigs excreted virus for a significantly shorter period and showed less clinical symptoms than pigs vaccinated with a control plasmid. The dose of $10^{5} \mathrm{pfu}$ of the virulent strain NIA3 induces severe signs of Aujeszky's disease and $50 \%$ of the non vaccinated spf pigs at an age of 6-16 weeks will die. We have challenged the pigs at an age of 26 weeks: at this age lethality is less but still severe signs of disease are induced (growth retardation, days of fever and clinical signs). A challenge at a young age is not useful as in the field maternal immunity still plays a dualistic role (protection and interference with vaccination). Secondly, there are less virulent strains in the pig population in the field (which cause no mortality). Therefore more relevant parameters for assessing vaccine induced protection are prevention of disease (growth retardation) and prevention of virus transmission (virus excretion and transmission). On the other hand, inbred mini pigs (haplotype $\mathrm{d} / \mathrm{d}$ ) are more susceptible for PRV infections. Vaccination with PRV-gD DNA fully protected against a challenge infection at an age of 24 weeks, whereas 2 out of 3 sham-vaccinated control mini-pigs died and the third control pig showed severe signs of disease (van Rooij et al., unpublished observations).

Recently, Gerdts et al. [30] demonstrated that pigs vaccinated with a plasmid encoding glycoprotein $\mathrm{C}$ of PRV survived a lethal challenge with PRV strain $75 \mathrm{~V} 19$ and showed partial protection against the highly virulent NIA-3 strain. However, protection was not observed after vaccination with the $\mathrm{gD}$ plasmid. Similarly, Monteil et al. [32] observed only weak Ab responses and no protection after DNA vaccination with PRV-gD in piglets. Such differences in outcome may in part be due to the choice of plasmid which may have lead to insufficient levels of protein expression resulting in less efficient stimulation of the immune system. The levels of neutralizing Abs obtained in our experiments were comparable with those observed after vaccination with conventional attenuated or inactivated whole virus vaccines $[31,19]$. Therefore our studies indicate that vaccination with this PRV-gD plasmid is capable of inducing strong humoral immunity in pigs. PRV-gD DNA induced $\mathrm{Ab}$ titres in mice, on the other hand, were relatively low as compared to conventional vaccine preparations which exert protection [21].

However, immunity against PRV in pigs is probably not solely based on VN Abs; cell-mediated immune re- 
sponses are also essential for providing antiviral immunity upon challenge infection. We have detected a PRV-specific lymphocyte proliferative response in pigs after vaccination with PRV-gD. These cell-mediated immune responses could be detected only after repeated vaccination. This slow lymphoproliferative response in pigs might have been caused by the fact that $\mathrm{gD}$ is not the prime antigenic determinant for the induction of cell mediated immune responses [28]. Other explanations for the slow induction of cell mediated immune responses could be the vaccine dose or the route of application [33]. Preliminary studies indicate that the intradermal route is more efficient in the induction of humoral and cell-mediated immune responses in pigs than the intramuscular route (van Rooij et al., unpublished observations). Pig skin, when injected with DNA, transiently expresses the injected gene at high levels in the epidermis [34].

Epitopes from DNA plasmid-expressed protein can be presented by major histocompatibility complex (MHC) class I molecules and thus elicit $\mathrm{CD} 8^{+}$cytotoxic T-lymphocyte (CTL) responses. However, studies on the role of CTL in immunity to PRV in pigs have been hampered by difficulties in measuring MHCrestricted cytotoxicity. Moreover, demonstrating MHC-restricted CTL may require antigen specific restimulation in vitro. Zuckermann et al., [35] have demonstrated that the major portion of the PRV specific CTLs that are induced by immunization with $\mathrm{PRV}$ are directed against $\mathrm{gC}$, while glycoproteins $\mathrm{gE}$, $\mathrm{gI}$ and $\mathrm{gX}$ play a minor role. Studies are undertaken to assess the possible role of $\mathrm{gD}$ in the induction of CTLs. Nonspecific killer cells on the other hand, e.g. activated by e.g. MHC class II restricted T-cells, may also be involved in the cytotoxic response which restricts viral replication [36]. Moreover, these $\mathrm{CD} 4^{+}$ T-cells may inhibit viral replication by production of cytokines with antiviral activity, such as IFN- $\gamma$ [37]. $\mathrm{CD}^{+}$T-cells have been implicated in the resistance against another alphaherpes virus, herpes simplex virus (HSV); Manickan et al. [7] demonstrated that in mice immunized with $\mathrm{HSV}-\mathrm{gB}$ DNA, a $\mathrm{CD}^{+}{ }^{+} \mathrm{T}$-cell response protected the animals from infection with HSV1.

Efficacy of PRV vaccines is still being based on their capacity to reduce clinical signs and virus excretion. The reduction in virus excretion obtained after DNA vaccination with PRV-gD is comparable to some of the commercial, conventional vaccines tested in vaccine evaluation trials at the ID-DLO. It is therefore expected that by improving the procedure for DNA vaccination, e.g. by gene gun delivery, specific targeting, use of an adjuvant or combining plasmids $[3,6,38,39]$, it will be possible to produce DNA vaccines which will be as efficient as live attenu- ated vaccines in preventing clinical disease and virus transmission.

The advantages of DNA immunization are the ease of manipulation by standard recombinant DNA techniques and the relative simple method for delivery and expression of the antigens. Therefore, using DNA vaccination it may be possible to scan the PRV genome for novel immunogens and test their capacity to elicit protective immunity in pigs. In addition, the potential of DNA vaccines to overcome the negative effect of maternally transferred immunity on the development of active immunity has to be assessed. It will even be possible to develop multidisease vaccines coding for immunorelevant antigens from several microbes and for immunomodulating molecules leading to vaccines which can confer protection against several pathogens.

\section{Acknowledgements}

We thank B. Peeters (ID-DLO, Lelystad, The Netherlands) for providing plasmid pMZ33 and Vical (San Diego, USA) for the generous gift of plasmid VR1012.

\section{References}

[1] Gustafson DP. Pseudorabies. In: Leman AD, Straw B, Glock RD, Mengelin WL, Penny RNC, Schull ES, editors. Disease of swine. Ames, Iowa: Iowa State University Press, 1986. p. 27489.

[2] Wolff JA, Malone RW, Williams P, Chong W, Acsadi G, Jani A, Felgner PL. Direct gene transfer into mouse muscle in vivo. Science 1990;247:1465-8.

[3] Williams RS, Johnston SA, Riedy M, DeVit MJ, McElligott $\mathrm{SG}$, Sanford JC. Introduction of foreign genes into tissues of living mice by DNA-coated microprojectiles. Proc Natl Acad Sci USA 1991;88:2726-30.

[4] Tang D, DeVit M, Johnston SA. Genetic immunization is a simple method for eliciting an immune response. Nature 1992;356:152-4.

[5] Ulmer JB, Donnelly JJ, Parker SE, Rhodes GH, Felgner PL, Dwarki VJ, Gromkowski SH, Deck RR, De Witt CM, Friedman A, Hawe LA, Leander KR, Martinez D, Perry HC, Shiver JW, Montgomery DL, Lui MA. Heterologous protection against influenza by injection of DNA encoding a viral protein. Science 1993;259:1745-9.

[6] Xiang Z, Ertl HCJ. Manipulation of the immune response to a plasmid-encoded viral antigen by coinoculation with plasmids expressing cytokines. Immunity 1995;2:129-35.

[7] Manickan E, Rouse RJ, Yu Z, Wire WS, Rouse BT. Genetic immunization against herpes simplex virus. Protection is mediated by CD4 + T-lymphocytes. J Immunol 1995;155:25965.

[8] Bourne N, Stanberry LR, Bernstein DI, Lew D. DNA immunization against experimental genital herpes simplex virus infection. J Infect Dis 1996;173:800-7.

[9] Martins LP, Lau LL, Asano MS, Ahmed R. DNA vaccination against persistent viral infection. J Virol 1995;69:2574-82. 
[10] Yokoyama M, Zhang J, Whitton JL. DNA immunization confers protection against lethal lymphocytic choriomeningitis virus infection. J Virol 1995;69:2684-8.

[11] González Armas JC, Morello CS, Cranmer LD, Spector DH. DNA immunization confers protection against murine cytomegalovirus infection. J Virol 1996;70:7921-8.

[12] Donnelly JJ, Martinez D, Jansen KU, Ellis RW, Montgomery DL, Liu MA. Protection against papilloma virus with a polynucleotide vaccine. J Infect Dis 1996;173:314-20.

[13] Cox GJ, Zamb TJ, Babiuk LA. Bovine herpesvirus 1: immune responses in mice and cattle injected with plasmid DNA. J Virol 1993;67:5664-7.

[14] Yasutomi Y, Robinson HL, Lu S, Mustafa F, Lekutis C, Arthos J, Mullins JI, Voss G, Manson K, Wyand M, Letvin NL. Simian immunodeficiency virus-specific cytotoxic T-lymphocyte induction through DNA vaccination of rhesus monkeys. J Virol 1996;70:678-81.

[15] Lu S, Arthos J, Montefiori DC, Yasutomi Y, Manson K, Mustafa F, Johnson E, Santoro JC, Wissink J, Mullins JI, Haynes JR, Letvin NL, Wyand M, Robinson HL. Simian immunodeficiency virus DNA vaccine trial in macaques. J Virol 1996;70:3978-91.

[16] Marchioli CC, Yancey RJ, Petrovskis EA, Timmins JG, Post LE. Evaluation of pseudorabies virus glycoprotein gp50 as a vaccine for Aujeszky's disease in mice and swine; expression by vaccinia virus and chinese hamster ovary cells. J Virol 1987;61:3977-82.

[17] Ishii H, Kobayashi Y, Kuroki M, Kodama Y. Protection of mice from lethal infection with Aujesky's disease virus by immunisation with purified gVI. J Gen Virol 1988;69:1411-4.

[18] Riviere M, Tartaglia J, Perkus ME, Norton EK, Molnar Bongermino C, Lacoste F, Duret C, Desmettre P, Paoletti E. Protection of mice and swine from pseudorabies virus conferred by vaccinia virus-based recombinants. J Virol 1992;66:3424-34.

[19] Kimman TG. Comparative efficacy of three doses of the genetically engineered Aujesky's disease virus vaccine strain 783 in pigs with maternal antibodies. Vaccine 1992;10:363-5.

[20] Peeters B, Bouma A, de Bruin T, Moormann R, Gielkens A, Caiman T. Non transmissible pseudorabies virus gp50 mutants: a new generation of safe live vaccines. Vaccine 1994;12:375-80.

[21] Schijns VECJ, Haagmans BL, Horzinek MC. IL-12 stimulates an antiviral type 1 cytokine response but lacks adjuvant activity in IFN- $\gamma$-receptor-deficient mice. J Immunol 1995;155:2525-32.

[22] Raugh LF, Mettenleiter TC. Pseudorabies virus glycoproteins gII and gp50 are essential for virus penetration. J Virol 1991;65:5348-56.

[23] Peeters B, Pol J, Gielkens A, Moorman R. Envelope glycoprotein gp50 of pseudorabies virus is essential for virus entry but is not required for viral spread in mice. $J$ Virol 1993;67:170-7.

[24] Eliot M, Fargeaud D, L'Haridon R, Toma B. Identification of pseudorabies virus glycoprotein gp50 as a major target of neutralizing antibodies. Arch Virol 1988;99:45-56.

[25] Wathen LMK, Platt KB, Wathen MW, VanDeusen RA, Whetstone CA, Pirtle EC. Production and characterization of monoclonal antibody directed against pseudorabies virus. Virus Res 1985;4:19-29.
[26] McFerran JB, Dow C. Studies on immunisation of pigs with the Bartha strain of Aujeszky disease virus. Res Vet Sci 1975; 19:17-22.

[27] Peeters B, de Wind N, Hooisma M, Wagenaar F, Gielkens A, Moormann R. Pseudorabies virus envelope glycoproteins gp50 and gII are essential for virus penetration, but only gII is involved in membrane fusion. J Virol 1992;66:894-905.

[28] Kimman TG, De Bruin TGM, Voermans JJM, Peeters BPH, Bianchi ATJ. Development and antigen specificity of the lymphoproliferation response of pigs to pseudorabies virus: dichotomy between secondary B- and T-cell responses. Immunology 1995;86:372-8.

[29] Bitsch V, Eskildsen M. A comparative examination of swine sera for antibody to Aujesky virus with the conventional and modified virus serum neutralization test and a modified complement fixation test. Acta Vet Scan 1976;17:142-5.

[30] Gerdts V, Jons A, Makoschey B, Visser N, Mettenleiter TC. Protection of pigs against Aujeszky's disease by DNA vaccination. J Gen Virol 1997;78:2139-46.

[31] Vannier P, Hutet E, Bourgueil E, Cariolet R. Level of virulent virus excreted by infected pigs previously vaccinated with different glycoprotein deleted Aujeszky's disease vaccines. Vet Micr 1991;29:213-23.

[32] Monteil M, Le Potier MF, Guillotin J, Cariolet R, Houdayer C, Eliot M. Genetic immunization of seronegative one-day-old piglets against pseudorabies induces neutralizing antibodies but not protection and is ineffective in piglets from immune dams. Vet Res 1996;27:443-52.

[33] Pertmer TM, Roberts TR, Haynes JR. Influenza virus nucleoprotein-specific immunoglobulin $G$ subclass and cytokine responses elicited by DNA vaccination are dependent on the route of vector DNA delivery. J Virol 1996;70:6119-25.

[34] Hengge UR, Walker PS, Vogel JC. Expression of naked DNA in human, pig, and mouse skin. J Clin Invest 1996;97:2911-6.

[35] Zuckermann FA, Zsak L, Mettenleiter T, Ben-Porat T. Pseudorabies virus glycoprotein gIII is a major target antigen for murine and swine virus-specific cytotoxic T-lymphocytes. J Virol 1990;64:802-12.

[36] Kimman TG, De Bruin TGM, Voermans JJM, Bianchi ATJ. Cell- mediated immunity to pseudorabies virus: cytolytic effector cells with characteristics of lymphokine-activated killer cells lyse virus-infected and glycoprotein $\mathrm{gB}$ - and $\mathrm{gC}$ - transfected L14 cells. J Gen Virol 1996;77:987-90.

[37] Schijns VECJ, Van Der Neut R, Haagmans BL, Bar DR, Schellekens $\mathrm{H}$, Horzinek MC. Tumour necrosis factor- $\alpha$, interferon- $\gamma$ and interferon- $\beta$ exert antiviral activity in nervous tissue cells. J Gen Virol 1991;72:809-15.

[38] Sato Y, Roman M, Tighe H, Lee D, Corr M, Nguyen MD, Silverman GJ, Lotz M, Carson DA, Raz E. Immunostimulatory DNA sequences necessary for effective intradermal gene immunization. Science 1996;273:352-4.

[39] Chow Y-H, Huang WL, Chi W-K, Chu Y-D, Tao M-H. Improvement of hepatitis B virus DNA vaccines by plasmids coexpressing hepatitis B surface antigen and interleukin-2. J Virol 1997;71:169-78. 